\title{
Prevalence and determinants of polypharmacy in Switzerland: data from the CoLaus study
}

\author{
Julien Castioni* ${ }^{*}$, Pedro Marques-Vidal, Nazanin Abolhassani, Peter Vollenweider and Gérard Waeber
}

\begin{abstract}
Background: Polypharmacy is a frequent condition, but its prevalence and determinants in the Swiss mid-aged population are unknown. We aimed to evaluate the prevalence and determinants of polypharmacy in a large Swiss mid-aged population-based sample.

Methods: Data from 4938 participants of the CoLaus study (53\% women, age range 40-81 years) were collected between 2009 and 2012. Polypharmacy was defined by the regular use of five or more drugs.

Results: Polypharmacy was reported by 580 participants $[11.8 \%, 95 \%$ confidence interval $(10.9 ; 12.6)]$. Participants on polypharmacy were significantly older (mean \pm standard deviation: $66.0 \pm 9.1$ vs. $56.6 \pm 10.1$ years), more frequently obese (35.9\% vs. $14.7 \%)$, of lower education ( $66.6 \%$ vs. $50.7 \%)$ and former smokers (46.7\% vs. $36.4 \%)$ than participants not on polypharmacy. These findings were confirmed by multivariate analysis: odds ratio and ( $95 \%$ confidence interval) for age groups 50-64 and 65-81 relative to 40-49 years: $2.90(2.04 ; 4.12)$ and $10.3(7.26 ; 14.5)$, respectively, $\mathrm{p}$ for trend $<0.001$; for low relative to high education: $1.56(1.17 ; 2.07)$; for overweight and obese relative to normal weight participants: $2.09(1.65 ; 2.66)$ and $4.38(3.39 ; 5.66)$, respectively, $p$ for trend $<0.001$; for former and current relative to never smokers: $1.42(1.14,1.75)$ and $1.63(1.25,2.12)$, respectively, $p$ for trend $<0.001$.

Conclusion: One out of nine participants of our sample is on polypharmacy. Increasing age, body mass index, smoking and lower education independently increase the likelihood of being on polypharmacy.
\end{abstract}

Keywords: Polypharmacy, Socio-economic, Smoking, Epidemiology

\section{Background}

In industrialized countries, population ageing is paralleled by an increase in the number of drugs prescribed $[1,2]$. An increasing number of subjects are with polypharmacy, defined as the regular intake of five or more medicines [1-3]. The prevalence of polypharmacy is believed to have doubled during the last decade [2,3]. Still, the reported prevalence rates vary considerably, from $10 \%$ in a study conducted in 2006 in the Greek general population [4] to $75 \%$ in a study conducted in 2012 in the Austrian nurse care system [5].

Several factors have been shown to be associated with polypharmacy. Ageing and its associated multimorbidities are the most important [6-9]. The prevalence

\footnotetext{
* Correspondence: Julien.Castioni@chuv.ch

Department of Medicine, Internal Medicine, Lausanne university hospital, Rue du Bugnon 46, 1011 Lausanne, Switzerland
}

of polypharmacy can be as high as $60 \%$ in the general population aged over 65 years $[10,11]$, although high prevalence rates have also been reported for younger people $[2,3,12,13]$. Indeed, two thirds of all individuals with polypharmacy are under 70 years old [14]. Current and/or former smoking and obesity have also been positively associated with polypharmacy $[4,15]$, while the effect of education is controversial, as higher levels of polypharmacy have been reported among high [4] or low $[6,16]$ educational groups, while even other studies found no differences between educational groups [17].

Polypharmacy increases the probability of drug-drug interactions and adverse drug reactions [3] and is associated with a higher risk of falls, hospitalisation, poor functional status, morbidity and mortality [18-20]. Nevertheless, polypharmacy might be necessary and beneficial to the 
patient if adequately prescribed [21, 22], and only inappropriate polypharmacy should be reduced [23].

From a clinical and public health perspective, it is important to evaluate the prevalence of polypharmacy in the mid-aged population, as it is a marker of multimorbidity and of potential adverse drug reactions. Further, with the exception of a study which focused on polypharmacy using health reimbursement claims [12, 24], no information is available regarding the prevalence and determinants of polypharmacy in the Swiss mid-aged population.

Our study aimed to: 1) assess the prevalence of polypharmacy in the Swiss mid-aged population; and 2) identify the individual and socio-economic factors associated with polypharmacy. We also assessed the type of drugs most commonly prescribed to patients with polypharmacy.

\section{Methods}

\section{Study population and design}

The Colaus study (www.colaus.ch) is an ongoing prospective survey investigating the biological and genetic determinants of cardiovascular disease in the population of Lausanne, Switzerland. Detailed descriptions of the study design have been reported elsewhere [25]. A simple, non-stratified random sample of 19,830 subjects (corresponding to $35 \%$ of the source population) was drawn [25]. Inclusion criteria were: (a) written informed consent and (b) willingness to take part in the examination and to provide blood samples.

The baseline study was conducted between 2003 and 2006 and included 6733 participants, with a participation rate of $41 \%$; the first follow-up was conducted between April 2009 and September 2012, five and a half year on average after the baseline and included 5064 participants (75.2\%) [26].

The baseline evaluation included an interview, a physical exam, blood sampling and a set of questionnaires. All participants were interviewed by trained recruiters regarding personal and family history of cardiovascular disease and risk factors and medicines taken. The questionnaires can be obtained from the authors upon request. The same procedure (questionnaires, interview and physical examination) was applied at follow-up. The data from the first follow-up was used in this study.

\section{Ethical statement}

This study was conducted according to the guidelines laid down in the Declaration of Helsinki and all procedures involving human subjects were approved by the Institutional Ethics Committee of the University of Lausanne (decision reference 33/09). Written informed consent was obtained from all participants.

\section{Clinical and biological parameters}

CVD and medication status were assessed by questionnaire. Smoking status was defined as never, former (irrespective of the time since quitting) and current (irrespective of the amount smoked). Educational level was categorized as low (obligatory school or apprenticeship), medium (high school), or high (university degree). Marital status was dichotomized into living alone (single, divorced, widowed) and living with somebody (married or partnership). Country of birth was categorized into Switzerland and other [25]. Body weight and height were measured with participants standing without shoes in light indoor clothes. Body weight was measured in kilograms to the nearest $100 \mathrm{~g}$ using a Seca ${ }^{\circ}$ scale, which was calibrated regularly. Height was measured to the nearest $5 \mathrm{~mm}$ using a Seca ${ }^{\circ}$ height gauge [25]. Body mass index (BMI) was defined as weight/height2. Overweight was defined as $25 \leq \mathrm{BMI}<30 \mathrm{~kg} / \mathrm{m} 2$ and obesity as $\mathrm{BMI} \geq 30 \mathrm{~kg} / \mathrm{m} 2$ Venous blood samples $(50 \mathrm{ml})$ were drawn after an over-night fast, and most clinical chemistry assays were performed by the CHUV Clinical Laboratory on fresh blood samples. Measurements included blood lipids, liver markers, cytokines and adipokines.

\section{Polypharmacy}

Participants were asked to bring all their medicines, which were checked by the research assistants. Participants were asked if the medicines were prescribed by a doctor or obtained over the counter. The regular consumption of the medicines over the last six months was also queried. Posology was not taken into account, i.e. a patient with propranolol $3 \times 40 \mathrm{mg}$ a day was considered as taking a single drug.

Polypharmacy was defined as the regular use of five or more different pharmacologically active medicines, regardless if a medicine contained one or more components [21, 27]. Excessive polypharmacy was defined as the regular use of ten or more medicines [6]. Regular use was defined as a medicine taken regularly over the past six months. Only medicines considered as medically needed (i.e. prescribed by a doctor) were considered; hence, we excluded medicines obtained over the counter, alternative therapies such as plant extracts, dietary supplements and homeopathy.

\section{Exclusion criteria}

Participants were excluded if they missed any information regarding individual, clinical or socio-economic data.

\section{Statistical analysis}

Statistical analyses were performed using Stata version 14.1 (Stata Corp, College Station, Texas, USA). Descriptive 
results were expressed as mean \pm standard deviation (SD) for continuous variables or as number of participants (percentage) for categorical variables. For prevalences, exact 95\% confidence intervals were also computed. Bivariate analysis was performed using Student's t-test for continuous variables and chi-square test for categorical variables. Multivariate analysis was performed using logistic regression and results were expressed as multivariate-adjusted odds ratio (OR) and [95\% confidence interval (CI)]. Statistical significance was considered for a two-sided test with $p<0.05$. Two sensitivity analyses were performed: the first one included over the counter (OTC) drugs, and the second considered all active substances among prescribed and OTC drugs. As some drugs combine several pharmacologically different active substances, we identified the ATC codes corresponding to combinations of different active substances (Additional file 1: Table S1), excluding combinations of vitamins and minerals (ATC codes A11A; A11C; A11D; A11E; A11G, A11J; A12AX; B03AD and B03AE). Categories were defined similarly to polypharmacy, i.e. $0-4, \geq 5$ and $\geq 10$ active substances.

\section{Results}

\section{Selection procedure and characteristics of participants}

Of the 5064 participants at follow-up, 126 (2.5\%) were excluded due to missing data for socio-economic characteristics or body mass index, leaving 4938 participants (97.5\%) for the current analysis. The characteristics of the included and excluded participants are summarized in Additional file 1: Table S2. Excluded participants lived more frequently alone, while no differences were found for the other individual and socio-economic characteristics.

\section{Prevalence of polypharmacy}

Prevalence of any drug use, polypharmacy and excessive polypharmacy are summarized in Table 1. Almost six out of ten $(59.7 \%)$ participants reported taking at least one drug; one out of nine (11.8\%) was with polypharmacy, and slightly over $1 \%(1.4 \%)$ was on excessive polypharmacy (Table 1). Cardiovascular drugs were the most frequent, being prescribed to over one third (37.3\%) of the participants; psychiatric drugs ranked second highest, being prescribed to one sixth (15.8\%) of the participants. Among cardiovascular drugs, the two most frequently prescribed categories were antihypertensive and hypolipidemic drugs (Table 1).

\section{Determinants of polypharmacy}

The distribution of the number of drugs consumed according to age groups is indicated in Fig. 1; the older the participant, the more drugs he/she consumed, with a considerable increase in the prevalence of polypharmacy.
The bivariate and multivariate analyses of the individual and socioeconomic determinants of polypharmacy are summarized in Table 2. Participants with polypharmacy were older, had a higher BMI, were less well educated, and were more frequently former smokers. These findings were further confirmed by multivariate analysis including all determinants simultaneously (Table 2). Conversely, no association was found between polypharmacy and gender, marital status or country of birth (Table 2). Similar findings were obtained for participants reporting excessive polypharmacy, although the association with smoking was no longer significant (Additional file 1: Table S3).

\section{Sensitivity analysis}

When OTC drugs were considered, the prevalence rates of polypharmacy and excessive polypharmacy were $14.7 \%$ and $1.8 \%$, respectively. The results of the multivariate analysis are provided in Additional file 1: Table S4 and Additional file 1: Table S5. Similar associations were found as for the original analysis; further, men had a lower likelihood of being on polypharmacy (Additional file 1: Table S4), while no gender differences were found for excessive polypharmacy (Additional file 1: Table S5).

When all active substances were considered (including active substances in OTC drugs), the prevalence rate of taking $\geq 5$ active substances/day was $16.9 \%$ and of taking $\geq 10$ active substances/day was $2.3 \%$. The results of the multivariate analysis using active substances are provided in Additional file 1: Table S6 and Additional file 1: Table S7. Results were similar to the previous sensitivity analysis; further, living in a couple was associated with a lower likelihood of taking $\geq 10$ active substances/day (Additional file 1: Table S7).

\section{Discussion}

There are few studies on the prevalence and the determinants of polypharmacy and excessive polypharmacy in the Swiss mid-aged population [12, 28]. Our results show that one out of nine (11.8\%) participants aged between 40 and 81 is on polypharmacy, but that less than two out of one hundred (1.4\%) are on excessive polypharmacy. Increasing age, body mass index, and lower education independently increase the likelihood of being with polypharmacy or on excessive polypharmacy; a positive association between smoking and polypharmacy was also found.

\section{Prevalence of polypharmacy}

The overall prevalence of polypharmacy was $11.8 \%$, and it increased considerably with age, from $2.9 \%$ for age group $40-49$ to $25.5 \%$ for age group $65-81$. Comparison with the literature is difficult as there are differences on how data were collected, in the age groups and, 
Table 1 Prevalence of polypharmacy and of the main drugs prescribed, Colaus study, Switzerland, 2009-2012, 4938 participants

\begin{tabular}{|c|c|c|}
\hline & Frequency n (\%) & $95 \% \mathrm{Cl}$ \\
\hline Any drug & $2947(59.7)$ & $(58.3-61.1)$ \\
\hline Polypharmacy ( $\geq 5$ drugs) & $580(11.8)$ & $(10.9-12.7)$ \\
\hline Excessive polypharmacy ( $\geq 10$ drugs) & $69(1.4)$ & $(1.1-1.8)$ \\
\hline Cardiovascular & $1843(37.3)$ & $(36.0-38.7)$ \\
\hline Antihypertensive drugs & $1327(26.9)$ & $(25.6-28.1)$ \\
\hline Angiotensin receptor blockers & $644(13.0)$ & $(12.1-14.0)$ \\
\hline Beta-blockers & $444(9.0)$ & $(8.2-9.8)$ \\
\hline Angiotensin converting enzyme inhibitors & $350(7.1)$ & $(6.4-7.8)$ \\
\hline Calcium channel blockers & $229(4.6)$ & $(4.1-5.3)$ \\
\hline Diuretics & $158(3.2)$ & $(2.7-3.7)$ \\
\hline Other & $81(1.6)$ & $(1.3-2.0)$ \\
\hline Hypolipidemic drugs & $1029(20.8)$ & $(19.7-22.0)$ \\
\hline Statins & $861(17.4)$ & $(16.4-18.5)$ \\
\hline Other hypolipidemic drugs & $219(4.4)$ & $(3.9-5.0)$ \\
\hline Antiplatelet drugs & $572(11.6)$ & $(10.7-12.5)$ \\
\hline Aspirin & $527(10.7)$ & $(9.8-11.6)$ \\
\hline Vitamin $\mathrm{K}$ antagonists & $108(2.2)$ & $(1.8-2.6)$ \\
\hline Psychiatric & $781(15.8)$ & $(14.8-16.9)$ \\
\hline Antidepressants & $516(10.5)$ & $(9.6-11.3)$ \\
\hline Anxiolytics & $243(4.9)$ & $(4.3-5.6)$ \\
\hline Hypnotics and sedatives & $230(4.7)$ & $(4.1-5.3)$ \\
\hline Antipsychotics & $54(1.1)$ & $(0.8-1.4)$ \\
\hline Analgesics & $657(13.3)$ & $(12.4-14.3)$ \\
\hline Anilides & $110(2.2)$ & $(1.8-2.7)$ \\
\hline Non-steroidal anti-inflammatory drugs & $447(9.1)$ & $(8.3-9.9)$ \\
\hline Opioids & $61(1.2)$ & $(0.9-1.6)$ \\
\hline Vitamins and minerals & $616(12.5)$ & $(11.6-13.4)$ \\
\hline Gastro-intestinal Drugs & $469(9.5)$ & $(8.7-10.3)$ \\
\hline Antiacids & $351(7.1)$ & $(6.4-7.9)$ \\
\hline Drugs for constipation & $68(1.4)$ & $(1.1-1.7)$ \\
\hline Other $^{a}$ & $114(2.3)$ & $(1.9-2.8)$ \\
\hline Antidiabetic drugs & $274(5.6)$ & $(4.9-6.2)$ \\
\hline Oral antidiabetics & $252(5.1)$ & $(4.5-5.8)$ \\
\hline Insulin & $59(1.2)$ & $(0.9-1.5)$ \\
\hline
\end{tabular}

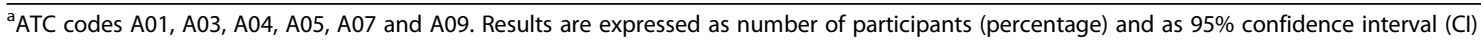

definitions of polypharmacy [29]. In Switzerland, a study based on claims from the largest health insurance reported a prevalence of polypharmacy of $16.7 \%$ among adults, and of $41.2 \%$ in individuals aged $\geq 65$ years [12]. The prevalence was based on health claims, and only subjects who asked for reimbursement of at least one drug were included. The other Swiss study was based on patients followed in a university primary care setting and reported prevalence rates ranging between $20.8 \%$ for age group $50-54$ and $54.6 \%$ for age group $75-80$ [28]. A
Scottish study based on electronic data from pharmacy claims reported an overall prevalence of polypharmacy of $22.1 \%$ in individuals aged $\geq 20$ years [3], while an Irish study using the same methodology reported a prevalence of $21.5 \%$ in individuals aged $\geq 20$ years; $30.2 \%$ for age group [45-64] and $60.4 \%$ in individuals aged $\geq 65$ years [11]. A possible explanation for these higher values is that individuals consuming "occasional" drugs such as antibiotics or anti-histaminics were also included. Similarly, in another Scottish study, the prevalence of 


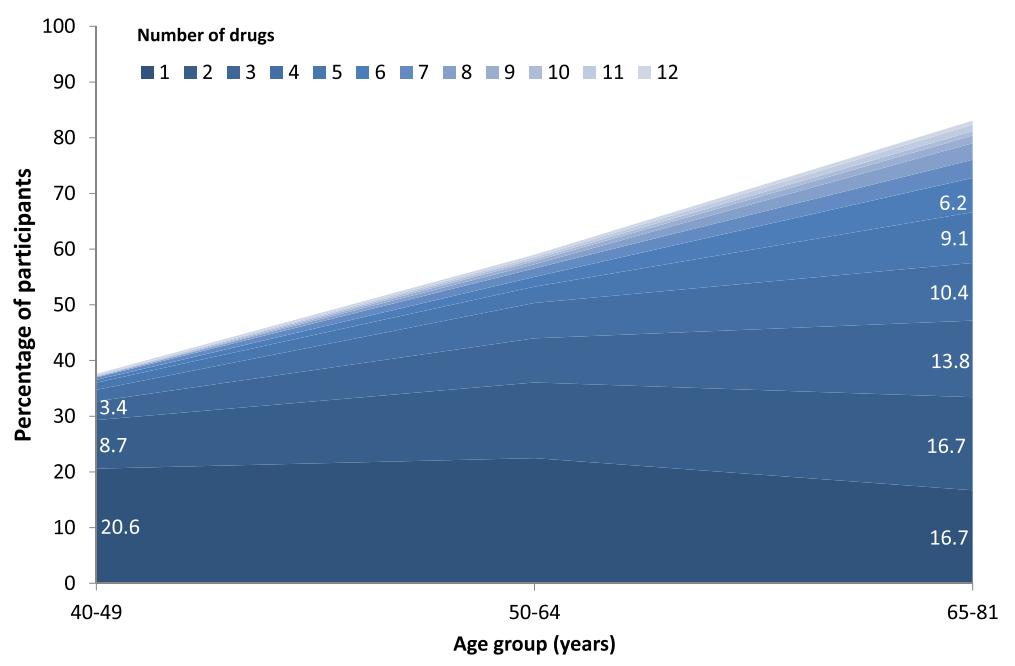

Fig. 1 Frequency of drug intake according to age group, in the 4938 participants of the CoLaus study, Switzerland

polypharmacy was $36 \%$ for age group [60-70]; this higher prevalence could be due to a different definition of polypharmacy, i.e. $\geq 4$ instead of $\geq 5$ drugs [13]. Overall, our results indicate that prevalence of polypharmacy is common in the Swiss mid-aged population, and that almost one quarter of individuals aged 65-81 years are with polypharmacy.

\section{Determinants of polypharmacy}

Increased age was associated with increased polypharmacy and excessive polypharmacy, a finding consistently reported in the literature $[1,2,11-13]$. This reflects the increase in the number of pathologies requiring therapy with ageing, or the difficulty to stop treatment once it has been initiated, leading to cumulative prescriptions. Still, the fact that four out of ten participants aged 65-81 were with polypharmacy stresses the need for the optimization of the prescriptions, such as using for example of the START/STOPP criteria [30], the adoption of a patientcentered rather than a disease-centered approach, and an effective physician-patient communication [31].

Increased body mass index was associated with increased polypharmacy and excessive polypharmacy rates, a finding also in agreement with the literature [4, 32]. A likely explanation is the wide array of comorbidities associated with obesity, namely diabetes, hypertension, dyslipidemia and arthrosis, which frequently require multiple treatments [33].

Participants with a lower education level presented higher rates of polypharmacy. Such association has already been reported, but mostly among elderly subjects $[6,10,16]$. An explanation is that subjects with a lower education level tend to present higher multimorbidity rates $[8,9]$, possibly due to adverse socio-economic conditions or to less interest for preventive measures. Still, our results suggest that even among middle aged subjects, a low educational level leads to increased rates of polypharmacy.

Smoking was associated with a higher prevalence of polypharmacy, a finding in accordance with another study [4]. Possible explanations include the higher prevalence of pulmonary, cancer and psychiatric disease among smokers, leading to the use of more drugs. Unfortunately, due the scope of the CoLaus study, detailed information regarding those diseases is not available and it would be of interest that this analysis be replicated.

\section{Classes of drugs}

Cardiovascular drugs were the most prescribed therapeutic class, a finding in agreement with the literature $[2,11,34]$. Antihypertensives ranked first, closely followed by statins. Possible explanations include the relatively high prevalence of cardiovascular risk factors in this population $[35,36]$ and the existence of guidelines regarding cardiovascular risk factor management [37-39]. Conversely, the high prevalence of psychiatric drugs (namely anxiolytics, hypnotics and sedatives) and of analgesics raises some concerns, as these drugs are not supposed to be prescribed on a long term basis.

\section{Sensitivity analysis}

Considering only the number of drugs prescribed might underestimate the prevalence of polypharmacy, as subjects can acquire other products over the counter. Considering also non-prescribed drugs increased the prevalence of polypharmacy from $11.8 \%$ to $14.7 \%$, but had no effect on its determinants.

Further, as drugs might contain combinations of active substances, simply counting the number of drugs (including OTC) might still underestimate the prevalence 
Table 2 Bivariate and multivariate analysis of the factors associated with polypharmacy ( $\geq 5$ different drugs/day), Colaus study, Switzerland, 2009-2012, 4938 participants

\begin{tabular}{|c|c|c|c|c|c|}
\hline & No $(n=4358)$ & Yes $(n=580)$ & $P$-value & Multivariate & P-value for trend \\
\hline Gender & & & 0.973 & & \\
\hline Woman & $2325(53.4)$ & $309(53.3)$ & & 1 (ref.) & \\
\hline Man & $2033(46.7)$ & $271(46.7)$ & & $0.92(0.75-1.12)$ & \\
\hline Age (years) & $56.6 \pm 10.1$ & $66.0 \pm 9.1$ & $<0.001$ & & \\
\hline Age group (\%) & & & $<0.001$ & & $<0.001$ \\
\hline $40-49$ & $1359(31.2)$ & $40(6.9)$ & & 1 (ref.) & \\
\hline $50-64$ & $1970(45.2)$ & $187(32.2)$ & & $2.90(2.04-4.12)$ & \\
\hline $65-81$ & 1029 (23.6) & $353(60.9)$ & & $10.3(7.26-14.5)$ & \\
\hline BMI categories (\%) & & & $<0.001$ & & $<0.001$ \\
\hline Normal + underweight & $2034(46.7)$ & $125(21.6)$ & & 1 (ref.) & \\
\hline Overweight & $1685(38.7)$ & $247(42.6)$ & & $2.09(1.65-2.66)$ & \\
\hline Obese & $639(14.7)$ & $208(35.9)$ & & $4.38(3.39-5.66)$ & \\
\hline Education (\%) & & & $<0.001$ & & 0.002 \\
\hline High & $995(22.8)$ & $70(12.1)$ & & 1 (ref.) & \\
\hline Middle & $1154(26.5)$ & $124(21.4)$ & & $1.15(0.83-1.58)$ & \\
\hline Low & $2209(50.7)$ & $386(66.6)$ & & $1.56(1.17-2.07)$ & \\
\hline Marital status (\%) & & & 0.121 & & \\
\hline Living alone & $1851(42.5)$ & $266(45.9)$ & & 1 (ref.) & \\
\hline Living in a couple & $2507(57.5)$ & $314(54.1)$ & & $0.86(0.71-1.05)$ & \\
\hline Born in Switzerland (\%) & & & 0.303 & & \\
\hline No & $1621(37.2)$ & $203(35.0)$ & & 1 (ref.) & \\
\hline Yes & $2737(62.8)$ & $377(65.0)$ & & $0.87(0.72-1.06)$ & \\
\hline Smoking status (\%) & & & $<0.001$ & & $<0.001$ \\
\hline Never & $1816(41.7)$ & $192(33.1)$ & & 1 (ref.) & \\
\hline Former & $1588(36.4)$ & $271(46.7)$ & & $1.42(1.14-1.75)$ & \\
\hline Current & 954 (21.9) & $117(20.2)$ & & $1.63(1.25-2.12)$ & \\
\hline
\end{tabular}

$B M I$ Body mass index. Bivariate analysis using chi-square for categorical variables and student's t-test for continuous variables; results are expressed as number of participants (column percentage) or as mean \pm standard deviation. Multivariate analysis using logistic regression; results are expressed as odds ratio and (95\% confidence interval)

rate of polypharmacy. Indeed, when all active substances were considered, the prevalence of participants taking $\geq 5$ active substances was $5.1 \%$ higher than the rate based on drugs ( $0.9 \%$ higher if at least 10 active substances). Again, no significant changes were found regarding the main determinants of taking $\geq 5$ active substances. Overall, our results suggest that the definition of polypharmacy (only prescribed drugs, prescribed + OTC or active substances) considerably impacts the prevalence rates but does not influence significantly its determinants. Studies assessing both polypharmacy and active substances in the general population are scarce and it would be of interest that our results be replicated in other settings.

\section{Clinical implications}

With the ageing of the population, the number of individuals with polypharmacy will increase. This will require general practitioners, hospital medical staff and pharmacists to be increasingly attentive to such a condition, in order to prevent over-prescription and the occurrence of drug-drug interactions and adverse drug reactions. In the forthcoming years, drug prescriptors and dispensers will be required to optimize prescriptions, a difficult task where the pros of adding an extra drug and the cons related to its possible adverse effects will have to be carefully balanced. Hence, it would be of interest that strategies aimed at optimizing polypharmacy are provided to health professionals either at the pre or at the postgraduate level. For instance, in Switzerland, there are initiatives aimed at reducing inappropriate polypharmacy that provide medication reconciliation to ambulatory patients [40]. Indeed, such strategies have been shown to reduce polypharmacy and its potential drug-drug interactions [41] and to be cost- 
saving [42]. Similarly, the use of medicines combining several drugs may tackle the treatment burden and improve adherence [43].

\section{Strengths and limitations}

This study has several strengths. Firstly, it was based on a large mid-aged population-based sample, allowing to estimate the prevalence of polypharmacy at the population level including non-prescribed (OTC) medicines, a condition that studies based on pharmacy claims cannot perform in Switzerland [3, 12]. Secondly, it clearly assessed drugs taken on a regular basis, precluding a possible overestimation bias due to the occasional consumption of drugs. Finally, and contrary to most studies $[1-3,6,10-12]$, several definitions for polypharmacy were applied, allowing a wider comparison with the existing literature [22].

This study has also some limitations. First, participation rate was low (41\%), but in line with other epidemiological studies [44]. Thus, a recruitment bias cannot be excluded, the healthiest participants being selected, which would underestimate the prevalence rates of polypharmacy and excessive polypharmacy. Still, the distribution of age groups in our sample was comparable to the source population and there was no difference in gender distribution between the source population and the CoLaus participants (not shown). Further, our results provide a conservative estimate for the prevalence rates of polypharmacy and excessive polypharmacy, and the fact that $25.6 \%$ of participants aged 65-81 were with polypharmacy (and $2.7 \%$ on excessive polypharmacy) is already concerning. Secondly, it was not possible to assess all comorbidities in our participants; hence, it was not possible to assess if (excessive) polypharmacy was due to increased number of comorbidities. Third, due to legal constraints, it was not possible to cross-check the information provided by the participants with data from medical or pharmaceutical electronic records. No specific training regarding drug collection was provided to the research assistants. Complete medication reconciliation or tools such as the Swiss polymedication check or the brown bags' method are difficult to apply in large samples due to economic and human resources issues [40, 45, 46]. However, recent studies suggest that self-reported information on medication use closely relates with pharmacy records [47]; hence, memory bias might be small and the impact on prevalence rates might be reduced.

\section{Conclusion}

In a Swiss mid-aged population-based sample, at least one out of nine participants of our sample is on polypharmacy. Age, body mass index, smoking and lower education independently increase the likelihood of being on polypharmacy.

\section{Additional file}

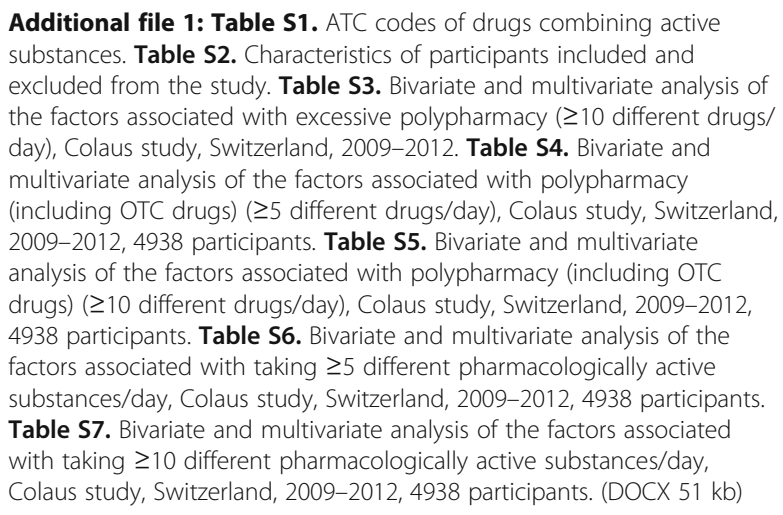

\section{Abbreviations}

BMI: Body Mass Index; CVD: Cardiovascular diseases; FU: Follow-up; OTC: Over the counter

\section{Funding}

This study is supported by research grants from the Swiss National Science Foundation [grant numbers 33CSCO-122,661; 33CS30-139,468 and 33CS30-148,401]

\section{Availability of data and materials}

The datasets generated and/or analyzed during the current study are not publicly available because no consent for public sharing of personal data was provided by the CoLaus. Metadata can be obtained from the authors upon request.

\section{Authors' contributions}

$J C$ had the initial idea, searched the literature, designed the analysis plan and wrote most of the article; PMV collected data, performed the statistical analysis and wrote part of the article; NA, PV and GW revised the article for important intellectual content. PMV had full access to the data and is the guarantor of the study. All authors read and approved the final manuscript.

\section{Ethics approval and consent to participate}

This study was conducted according to the guidelines laid down in the Declaration of Helsinki and all procedures involving human subjects were approved by the Institutional Ethics Committee of the University of Lausanne (decision reference 33/09). Written informed consent was obtained from all participants.

\section{Consent for publication \\ Not applicable.}

\section{Competing interests}

The authors report no competing interest.

\section{Publisher's Note}

Springer Nature remains neutral with regard to jurisdictional claims in published maps and institutional affiliations.

Received: 6 February 2017 Accepted: 13 December 2017 Published online: 21 December 2017

\section{References}

1. Hovstadius B, Hovstadius K, Astrand B, Petersson G. Increasing polypharmacy - an individual-based study of the Swedish population 20052008. BMC Clin Pharmacol. 2010;10:16.

2. Kantor ED, Rehm CD, Haas JS, Chan AT, Giovannucci EL. Trends in prescription drug use among adults in the United States from 1999-2012. JAMA. 2015;314(17):1818-31. 
3. Guthrie B, Makubate B, Hernandez-Santiago V, Dreischulte T. The rising tide of polypharmacy and drug-drug interactions: population database analysis 1995-2010. BMC Med. 2015;13:74.

4. Pappa E, Kontodimopoulos N, Papadopoulos AA, Tountas Y, Niakas D. Prescribed-drug utilization and polypharmacy in a general population in Greece: association with sociodemographic, health needs, healthservices utilization, and lifestyle factors. Eur J Clin Pharmacol. 2011; 67(2):185-92.

5. Alzner R, Bauer U, Pitzer S, Schreier MM, Osterbrink J, Iglseder B. Polypharmacy, potentially inappropriate medication and cognitive status in Austrian nursing home residents: results from the OSiA study. Wiener medizinische Wochenschrift (1946). 2016;166(5-6):161-5.

6. Wauters M, Elseviers M, Vaes B, Degryse J, Dalleur O, Vander Stichele R, Van Bortel L, Azermai M. Polypharmacy in a Belgian cohort of communitydwelling oldest old (80+). Acta Clin Belg. 2016;71(3):158-66.

7. Mayer S, Osterle A. Socioeconomic determinants of prescribed and nonprescribed medicine consumption in Austria. Eur J Pub Health. 2015;25(4): 597-603.

8. Pache B, Vollenweider P, Waeber G, Marques-Vidal P. Prevalence of measured and reported multimorbidity in a representative sample of the Swiss population. BMC Public Health. 2015;15:164.

9. Barnett K, Mercer SW, Norbury M, Watt G, Wyke S, Guthrie B. Epidemiology of multimorbidity and implications for health care, research, and medical education: a cross-sectional study. Lancet (London, England). 2012; 380(9836):37-43.

10. Walckiers D, Van der Heyden J, Tafforeau J. Factors associated with excessive polypharmacy in older people. Archives of public health $=$ Archives belges de sante publique. 2015;73:50.

11. Moriarty F, Hardy C, Bennett K, Smith SM, Fahey T. Trends and interaction of polypharmacy and potentially inappropriate prescribing in primary care over 15 years in Ireland: a repeated cross-sectional study. BMJ Open. 2015; 5(9):e008656.

12. Blozik E, Rapold R, von Overbeck J, Reich O. Polypharmacy and potentially inappropriate medication in the adult, community-dwelling population in Switzerland. Drugs Aging. 2013;30(7):561-8.

13. Payne RA, Avery AJ, Duerden M, Saunders CL, Simpson CR, Abel GA Prevalence of polypharmacy in a Scottish primary care population. Eur J Clin Pharmacol. 2014;70(5):575-81.

14. Hovstadius B, Astrand B, Petersson G. Dispensed drugs and multiple medications in the Swedish population: an individual-based register study. BMC Clin Pharmacol. 2009;9:11.

15. Charlesworth CJ, Smit E, Lee DS, Alramadhan F, Odden MC. Polypharmacy among adults aged 65 years and older in the United States: 1988-2010. The journals of gerontology Series A, Biological sciences and medical sciences. 2015;70(8):989-95.

16. Haider SI, Johnell $K$, Weitoft GR, Thorslund M, Fastbom J. The influence of educational level on polypharmacy and inappropriate drug use: a registerbased study of more than 600,000 older people. J Am Geriatr Soc. 2009; 57(1):62-9.

17. Gokce Kutsal Y, Barak A, Atalay A, Baydar T, Kucukoglu S, Tuncer T, Hizmetli S, Dursun N, Eyigor S, Saridogan M, et al. Polypharmacy in the elderly: a multicenter study. J Am Med Dir Assoc. 2009;10(7):486-90.

18. O'Mahony D, O'Sullivan D, Byrne S, O'Connor MN, Ryan C, Gallagher P. STOPP/START criteria for potentially inappropriate prescribing in older people: version 2. Age Ageing. 2015:44(2):213-8.

19. Cooper JA, Cadogan CA, Patterson SM, Kerse N, Bradley MC, Ryan C, Hughes CM. Interventions to improve the appropriate use of polypharmacy in older people: a Cochrane systematic review. BMJ Open. 2015;5(12):e009235.

20. Maher RL, Hanlon J, Hajjar ER. Clinical consequences of polypharmacy in elderly. Expert Opin Drug Saf. 2014;13(1):57-65.

21. Schottker B, Saum KU, Muhlack DC, Hoppe LK, Holleczek B, Brenner H. Polypharmacy and mortality: new insights from a large cohort of older adults by detection of effect modification by multi-morbidity and comprehensive correction of confounding by indication. Eur J Clin Pharmacol. 2017;

22. Cadogan CA, Ryan C, Hughes CM. Appropriate polypharmacy and medicine safety: when many is not too many. Drug Saf. 2016;39(2):109-16.

23. Patterson SM, Cadogan CA, Kerse N, Cardwell CR, Bradley MC, Ryan C, Hughes $C$ : Interventions to improve the appropriate use of polypharmacy for older people. The Cochrane database of systematic reviews 2014(10): cd008165.
24. Neuner-Jehle S. Polypharmacy, the new epidemic. Revue medicale suisse. 2016;12(518):942-7.

25. Firmann M, Mayor V, Vidal PM, Bochud M, Pecoud A, Hayoz D, Paccaud F, Preisig M, Song KS, Yuan X, et al. The CoLaus study: a population-based study to investigate the epidemiology and genetic determinants of cardiovascular risk factors and metabolic syndrome. BMC Cardiovasc Disord. 2008;8:6.

26. Antiochos P, Marques-Vidal P, McDaid A, Waeber G, Vollenweider P. Association between parental history and genetic risk scores for coronary heart disease prediction: the population-based CoLaus study. Atherosclerosis. 2016;244:59-65.

27. Viktil KK, Blix HS, Moger TA, Reikvam A. Polypharmacy as commonly defined is an indicator of limited value in the assessment of drug-related problems. Br J Clin Pharmacol. 2007:63(2):187-95.

28. Aubert CE, Streit S, Da Costa BR, Collet TH, Cornuz J, Gaspoz JM, Bauer D, Aujesky D, Rodondi N. Polypharmacy and specific comorbidities in university primary care settings. European journal of internal medicine. 2016;

29. Gillette C, Prunty L, Wolcott J, Broedel-Zaugg K. A new lexicon for polypharmacy: implications for research, practice, and education. Research in social \& administrative pharmacy : RSAP. 2015;11(3):468-71.

30. Tommelein E, Mehuys E, Petrovic M, Somers A, Colin P, Boussery K. Potentially inappropriate prescribing in community-dwelling older people across Europe: a systematic literature review. Eur J Clin Pharmacol. 2015; 71(12):1415-27.

31. Topinkova E, Baeyens JP, Michel JP, Lang PO. Evidence-based strategies for the optimization of pharmacotherapy in older people. Drugs Aging. 2012; 29(6):477-94.

32. Bardel A, Wallander MA, Svardsudd K. Reported current use of prescription drugs and some of its determinants among 35 to 65-year-old women in mid-Sweden: a population-based study. J Clin Epidemiol. 2000;53(6):637-43.

33. Davin C, Vollenweider P, Waeber G, Paccaud F, Marques-Vidal P. Cardiovascular risk factors attributable to obesity and overweight in Switzerland. Nutrition, metabolism, and cardiovascular diseases : NMCD. 2012;22(11):952-8

34. Qato DM, Wilder J, Schumm LP, Gillet V, Alexander GC. Changes in prescription and over-the-counter medication and dietary supplement use among older adults in the United States, 2005 vs 2011. JAMA Intern Med. 2016;176(4):473-82.

35. Danon-Hersch N, Marques-Vidal P, Bovet P, Chiolero A, Paccaud F, Pecoud A, Hayoz D, Mooser V, Waeber G, Vollenweider P. Prevalence, awareness, treatment and control of high blood pressure in a Swiss city general population: the CoLaus study. European journal of cardiovascular prevention and rehabilitation : official journal of the European Society of Cardiology, Working Groups on Epidemiology \& Prevention and Cardiac Rehabilitation and Exercise Physiology. 2009;16(1):66-72.

36. Firmann M, Marques-Vidal P, Paccaud F, Mooser V, Rodondi N, Waeber G, Vollenweider P. Prevalence, treatment and control of dyslipidaemia in Switzerland: still a long way to go. European journal of cardiovascular prevention and rehabilitation : official journal of the European Society of Cardiology, Working Groups on Epidemiology \& Prevention and Cardiac Rehabilitation and Exercise Physiology. 2010;17(6):682-7.

37. Mancia G, Fagard R, Narkiewicz K, Redon J, Zanchetti A, Bohm M, Christiaens T, Cifkova R, De Backer G, Dominiczak A, et al. 2013 ESH/ESC guidelines for the Management of Arterial Hypertension: the task force for the management of arterial hypertension of the European Society of Hypertension (ESH) and of the European Society of Cardiology (ESC). Eur Heart J. 2013:34(28):2159-219.

38. Catapano AL, Graham I, De Backer G, Wiklund O, Chapman MJ, Drexel H, Hoes AW, Jennings CS, Landmesser U, Pedersen TR, et al. 2016 ESC/EAS guidelines for the Management of Dyslipidaemias: the task force for the Management of Dyslipidaemias of the European Society of Cardiology (ESC) and European atherosclerosis society (EAS)developed with the special contribution of the European Assocciation for Cardiovascular Prevention \& Rehabilitation (EACPR). Eur Heart J. 2016;

39. Piepoli MF, Hoes AW, Agewall S, Albus C, Brotons C, Catapano AL, Cooney MT, Corra U, Cosyns B, Deaton C et al: 2016 European Guidelines on cardiovascular disease prevention in clinical practice: The Sixth Joint Task Force of the European Society of Cardiology and Other Societies on Cardiovascular Disease Prevention in Clinical Practice (constituted by representatives of 10 societies and by invited experts): Developed with the special contribution of the European Association for Cardiovascular Prevention \& Rehabilitation (EACPR). European journal of preventive cardiology 2016, 23(11):Np1-np96. 
40. Messerli M, Blozik E, Vriends N, Hersberger KE. Impact of a community pharmacist-led medication review on medicines use in patients on polypharmacy - a prospective randomised controlled trial. BMC Health Serv Res. 2016;16(1):145.

41. Tamura BK, Bell CL, Lubimir K, Iwasaki WN, Ziegler LA, Masaki KH. Physician intervention for medication reduction in a nursing home: the polypharmacy outcomes project. J Am Med Dir Assoc. 2011;12(5):326-30.

42. Kojima G, Bell C, Tamura B, Inaba M, Lubimir K, Blanchette PL, Iwasaki W, Masaki K: Reducing cost by reducing polypharmacy: the polypharmacy outcomes project. Journal of the American Medical Directors Association 2012, 13(9):818.e811-815.

43. Castellano JM, Sanz G, Penalvo JL, Bansilal S, Fernandez-Ortiz A, Alvarez L, Guzman L, Linares JC, Garcia F, D'Aniello F, et al. A polypill strategy to improve adherence: results from the FOCUS project. J Am Coll Cardiol. 2014;64(20):2071-82

44. Galea S, Tracy M. Participation rates in epidemiologic studies. Ann Epidemiol. 2007;17(9):643-53

45. Holbrook A, Bowen JM, Patel H, O'Brien C, You JJ, Tahavori R, Doleweerd J, Berezny T, Perri D, Nieuwstraten C, et al. Process mapping evaluation of medication reconciliation in academic teaching hospitals: a critical step in quality improvement. BMJ Open. 2016;6(12):e013663.

46. Sarzynski EM, Luz CC, Rios-Bedoya CF, Zhou S. Considerations for using the 'brown bag' strategy to reconcile medications during routine outpatient office visits. Qual Prim Care. 2014;22(4):177-87.

47. Drieling RL, LaCroix AZ, Beresford SA, Boudreau DM, Kooperberg C, Heckbert SR. Validity of self-reported medication use compared with pharmacy Records in a Cohort of older women: findings from the Women's Health Initiative. Am J Epidemiol. 2016;184(3):233-8.

\section{Submit your next manuscript to BioMed Central and we will help you at every step:}

- We accept pre-submission inquiries

- Our selector tool helps you to find the most relevant journal

- We provide round the clock customer support

- Convenient online submission

- Thorough peer review

- Inclusion in PubMed and all major indexing services

- Maximum visibility for your research

Submit your manuscript at www.biomedcentral.com/submit 